\title{
IMPACT OF ROAD TRAFFIC NOISE ON SLEEP DISTURBANCES AND ATTENTION DISORDERS AMONGST SCHOOL CHILDREN LIVING IN UPPER SILESIAN INDUSTRIAL ZONE, POLAND
}

\author{
MICHAŁ SKRZYPEK ${ }^{1}$, MAŁGORZATA KOWALSKA², ELŻBIETA M. CZECH ${ }^{1}$, EWA NIEWIADOMSKA ${ }^{1}$, \\ and JAN E. ZEJDA ${ }^{2}$
}

${ }^{1}$ Medical University of Silesia, Katowice, Poland

School of Public Health in Bytom, Department of Biostatistics

${ }^{2}$ Medical University of Silesia, Katowice, Poland

Medical Faculty in Katowice, Department of Epidemiology

\begin{abstract}
Objectives: Published reports suggest that some adverse health impact may be related to noise exposure, and motor vehicle traffic is considered to be the main source of environmental hazard of noise. The aim of this study has been to assess an association between occurrence of sleep and attention disorders with exposure to the noise generated by motor vehicle traffic in the case of a large group of children living in an urban environment. Material and Methods: The data was obtained using a cross sectional study design in Bytom (Silesia, Poland) from 2003-2007 for a selected group of 7-14 year olds $(\mathrm{N}=5136)$. The geographic information system was used for assessing the exposure to noise generated by the motor vehicle traffic. The association between occurrences of sleep disturbances or attention disorders and exposure to the traffic noise was examined by means of multivariable logistic regression. Results: Sleep disturbances and attention disorders were found to be statistically significantly associated with exposure to the traffic noise. The multivariable logistic regression results suggest that sleep disturbances and attention disorders were more likely to occur in the case of children living in the area with higher traffic density, the odds ratio $(\mathrm{OR})=1.44(95 \%$ confidence interval (CI): 1.05-1.97) and 1.38 (95\% CI: 1.03-1.86), respectively. Conclusions: The results of the study have confirmed that the exposure to the traffic noise could be a significant risk factor for sleep disturbances and attention disorders among children. Int J Occup Med Environ Health 2017;30(3):511-520
\end{abstract}

Key words:

Sleep, Child, Noise, Attention, Transportation, Automobiles

Funding: research was supported by the Medical University of Silesia in Katowice under grant KNW-1-036/N/3/0 entitled "Sleep disturbances in children living near main roads in the Bytom city." Grant manager: Michał Skrzypek, Ph.D.

Received: October 13, 2015. Accepted: May 12, 2016.

Corresponding author: M. Skrzypek, Medical University of Silesia, School of Public Health in Bytom, Department of Biostatistics, Piekarska 18, 41-902 Bytom, Poland (e-mail: mskrzypek@sum.edu.pl). 


\section{INTRODUCTION}

Quality of life depends on many environmental determinants. Recently published reports suggest that several adverse health effects, especially among urban dwellers, are related to noise exposure $[1,2]$. The main source of environmental noise is overall motor vehicle traffic including industry and neighbors (such as noise from animals, alarms, machines and domestic equipment, power and water infrastructure, noisy vehicles, pubs and clubs, etc.) that are also sources of this type of pollution [3-5].

Children are often vulnerable to environmental noise and the reduction in exposure to this type of noise is an important public health issue. Results from several studies confirm that children living in a noisy environment have lower cognitive performance [6,7], show frequent reading problems [8,9], exhibit lower mathematical skills $[10,11]$, and impaired memory $[8,12]$. It has also been shown that exposure to environmental noise may increase the prevalence of hypertension in the case of children [13-17].

At least 30\% of the European Union (EU) population live in areas where day-night average of road traffic noise level exceeds $55 \mathrm{~dB}$ [18]. Thus, traffic-related noise is considered to be a factor of adverse health effects like: sleep disorders [19], annoyance [7,20], as well as chronic cortisol increase [21] and elevated level of systolic pressure among children [22].

The lack of available data describing potential sleep disorders related to the environmental noise among Polish children has prompted the authors to undertake this study. This research, with the aim to assess the association of the occurrence of sleep and attention disorders with exposure to the noise generated by motor vehicle traffic in the case of a large group of children living in urban environment, was conducted in Bytom, a city located in central part of the Upper Silesian Industrial Zone, Poland.

\section{MATERIAL AND METHODS}

\section{Study population}

To assess the frequency of the occurrence of sleep and attention disorders, as well as confounding factors, we used data obtained from a cross-sectional study in 20032004 among all 7-14-year-old children attending primary schools in Bytom. Parents and legal guardians were asked to fill in a questionnaire constructed on the basis of the Polish version of the International Study of Asthma and Allergies in Childhood (ISAAC) questionnaire. The total number of forms administered to participants was 16356 with a response rate of $68.5 \%$. The database contains a total of 11209 records; out of which 4372 records were removed because of missing data in the scope of analyzed variables. Likewise, the following 1623 records from children living in the city centre were excluded due to significant differences in socio-economic and home environmental determinants (Table 1) as well as differences in urban geography - continuous building sites on both sides of the street (the so called street canyons). The group of the children included 35 of them who had lived in the city for shorter than one year, 17 - with hearing impairment, 3 - diagnosed with diabetes, and 23 - had epilepsy. After these exclusions, our finally analyzed database contained 5136 records.

\section{Outcomes and exposure assessment}

The definition of outcomes analyzed within the framework of the multivariable model, described further in this section, was based on the parental opinion on the health status of the child and included answers to questions: "Has the child ever had sleep disorders?" and "Has the child ever had attention disorders?"

Most published reports based on direct noise measurements or the individual noise exposure were estimated using noise dispersion models. Such a dispersion model was not employed for the city of Bytom within the studied time period. Scientific data suggests that noise levels in urban environment are correlated with traffic data [23]. 
Table 1. Characteristics of school children living in the Upper Silesian Industrial Zone, Poland, in the study of effect of road traffic noise on sleep disturbances and attention disorders, 2003-2007

\begin{tabular}{|c|c|c|c|}
\hline \multirow{2}{*}{ Characteristics } & \multicolumn{2}{|c|}{$\begin{array}{l}\text { Respondents } \\
{[\mathrm{n}(\%)]}\end{array}$} & \multirow{2}{*}{$\mathrm{p}$} \\
\hline & $\begin{array}{l}\text { studied children } \\
\quad(\mathrm{N}=5136)\end{array}$ & $\begin{array}{l}\text { non-participant children } \\
\quad(\mathrm{N}=1623)\end{array}$ & \\
\hline \multicolumn{4}{|l|}{ Demographics } \\
\hline females & $2635(51.3)$ & $831(51.2)$ & 0.94 \\
\hline$>9$ years old & $3754(73.1)$ & $1110(68.4)$ & $<0.01$ \\
\hline \multicolumn{4}{|l|}{ Socioeconomic status } \\
\hline low financial family standing & $2737(53.3)$ & $1019(62.8)$ & $<0.01$ \\
\hline \multicolumn{4}{|l|}{ Indoor environment } \\
\hline environmental tobacco smoke & $2748(53.5)$ & $982(60.5)$ & $<0.01$ \\
\hline crowding (> 1 person per room) & $3200(62.3)$ & $1079(66.5)$ & $<0.01$ \\
\hline
\end{tabular}

Therefore, we used surrogate indices of individual exposure to traffic-related noise representing residential distances from roads, traffic intensity and traffic density. To assess these surrogates of noise exposures, residential addresses from the questionnaire were used, with the municipal office in Bytom providing the data on traffic intensity along with spatial placement of industry plants and railways (Figure 1).

Data on traffic intensity was collected in the year 2007, however, road conditions and infrastructure had not changed significantly from the early 1990's until 2007. The only significant change is represented by higher traffic counts [24]. We only conducted the qualitative statistical analysis based on the following 3 scenarios used for categorizing subjects into either the exposure or control group: the scenario A: the distance from a child's residence to a major road (expressed as a categorical variable $\leq 100 \mathrm{~m}$ and $>100 \mathrm{~m}$ ); the scenario B: the highest traffic count within $100 \mathrm{~m}$ radius of the place of residence (expressed as a categorical variable $>$ 90th percentile and $\leq 90$ th percentile of traffic counts); and the scenario C: the traffic density within $100 \mathrm{~m}$ radius of the place of residence (expressed as a categorical variable $>90$ th percentile and $\leq 90$ th percentile of traffic densities). Calculations of these scenarios were performed by means of the geographic information system (ESRI ArcGIS, version 9.2) using previously described methods [25]. It is worth mentioning that a similar approach was utilized in the French RECORD (the Residential Environment and Coronary Heart Disease) study to assess adults' annoyance related to the road traffic noise [26].

\section{Statistical analysis}

Statistical significance of between-group differences for categorical variables was evaluated by means of the $\mathrm{Chi}^{2}$ test. Potential confounders like gender, age, respiratory diseases (yes/no), eczema (yes/no), household financial standing (good/poor), crowding (> 1 person per room), exposure to environmental tobacco smoke at home (yes/no), and exposure to industrial or railway noise (place of residence within $300 \mathrm{~m}$ - yes/no) were controlled in the multivariable logistic regression model. Correlation between explanatory variables was checked, and multicollinearity between confounders was assessed by means of tolerance and variance inflation factor (VIF). The stepwise forward selection method of model building was used, with significance level set to $p=0.3$ to 


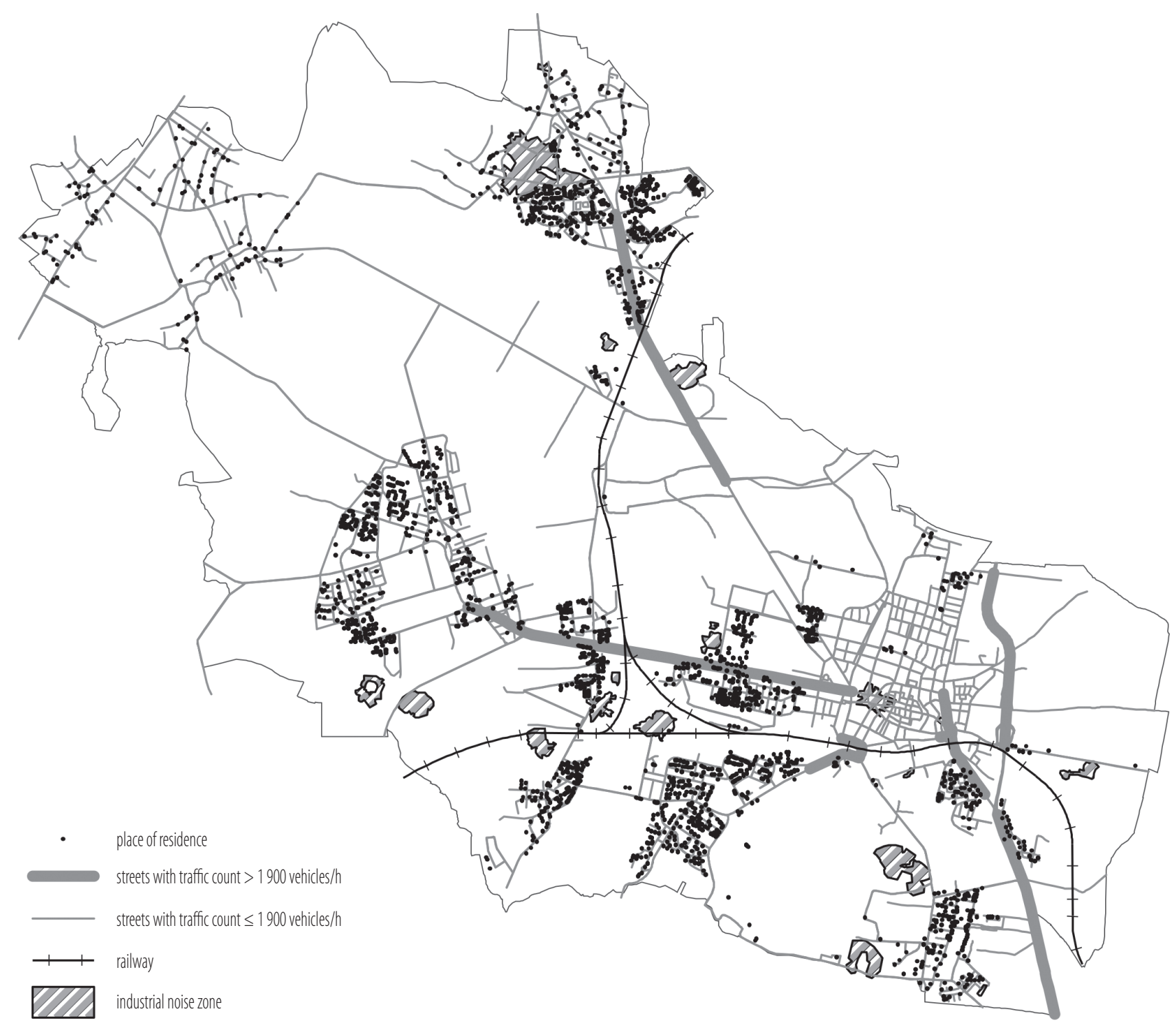

Fig 1. Bytom city

allow a confounder into the model, and significance level set to $p=0.1$ for a confounder to stay in the model $[27,28]$. The goodness of fit of the model was evaluated by means of the deviance and Pearson's Chi ${ }^{2}$ tests. Logistic odds ratio $(\log \mathrm{OR})$ and their $95 \%$ confidence intervals (CI) were calculated. Statistical significance level was set to $\alpha=0.05$. Statistical analyses were performed using procedures available in SAS, version 9.4 (SAS Institute Inc., Cary, NC).

\section{RESULTS}

Descriptive characteristics such as demographic data, family socioeconomic status, and the home environment of subjects (5136 children) are presented in the Table 1. The prevalence of sleep disturbances and attention disorders in the studied group was $8.24 \%(\mathrm{~N}=423)$ and $9.89 \%(\mathrm{~N}=508)$, respectively. Results of the categorization of studied children into the exposed and non-exposed group, according to the adopted 3 separate 


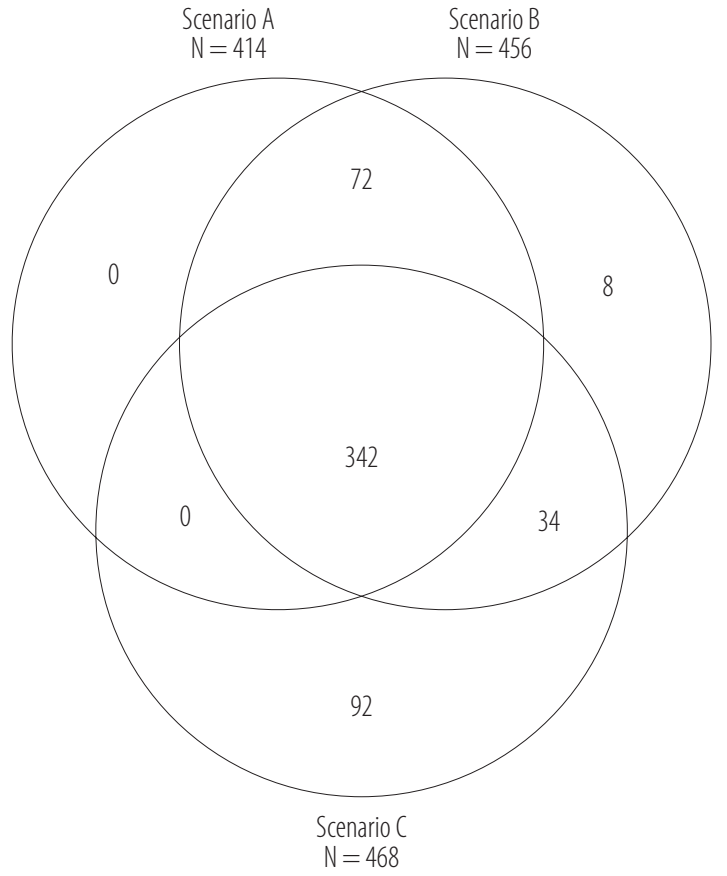

Scenario A: the distance from a child's residence to major road $\leq 100 \mathrm{~m}$; scenario B: living in the area where maximum traffic count within $100 \mathrm{~m}$ radius of the place of residence $>90$ th percentile of traffic counts; scenario $\mathrm{C}$ : the traffic density within $100 \mathrm{~m}$ radius of the place of residence $>90$ th percentile of traffic densities.

Fig 2. Exposed school children living in the Upper Silesian Industrial Zone, Poland, 2003-2007, in 3 different scenarios of exposure to road traffic noise - Venn diagram

scenarios of exposure, are shown in the Figure 2. The scenario A shows 414 participants living within $100 \mathrm{~m}$ away from the main road (the exposed group) and 4722 participants living $>100 \mathrm{~m}$ away from the main road (the control group). The scenario B shows 456 children living in the area where maximum traffic intensity within $100 \mathrm{~m}$ radius of the place of residence exceeds 90th percentile of traffic counts for all roads (the exposed group) and 4680 children living in the area with lower traffic intensity (the control group). Finally, the scenario $\mathrm{C}$ shows 468 children living in the area where traffic density within $100 \mathrm{~m}$ radius of the place of residence exceeds 90th percentile of the traffic density calculated for all roads (the exposed group) and 4668 children living in the area with lower traffic density (the control group). It is worth noting that the scenario $\mathrm{C}$ qualified the highest number of children into the exposed group whereas concordance between proposed scenarios in qualification into the exposed group was observed in the case of 342 children (Figure 2).

The frequency of sleep disturbances as well as attention disorders was statistically significantly higher in the exposed group; the scenario $\mathrm{C}$ of exposure is the best to describe the relationship between health disorders and hazards (Table 2). The remaining 2 scenarios (A and B) did not show statistically significant differences in the prevalence of these disorders.

The Figure 3 shows the results of the multivariable analysis of the relationship between health effects among children

Table 2. Prevalence of sleep and attention disorders among school children living in the Upper Silesian Industrial Zone, Poland, 2003-2007, according to traffic metrics

\begin{tabular}{|c|c|c|c|c|c|c|c|c|c|}
\hline \multirow{2}{*}{$\begin{array}{l}\text { Disorders } \\
\text { among children }\end{array}$} & \multicolumn{3}{|c|}{$\begin{array}{l}\text { Distance to the busy road } \\
\text { from a child's residence } \\
\qquad(\mathrm{N}=5136)\end{array}$} & \multicolumn{3}{|c|}{$\begin{array}{l}\text { Maximum traffic count within } 100 \mathrm{~m} \\
\text { of a child's residence } \\
(\mathrm{N}=5136)\end{array}$} & \multicolumn{3}{|c|}{$\begin{array}{l}\text { Traffic density within } 100 \mathrm{~m} \\
\text { of a child's residence } \\
(\mathrm{N}=5136)\end{array}$} \\
\hline & $\begin{array}{l}\leq 100 \mathrm{~m} \\
(\mathrm{~N}=414)\end{array}$ & $\begin{array}{c}>100 \mathrm{~m}^{\mathrm{a}} \\
(\mathrm{N}=4722)\end{array}$ & $\mathrm{p}$ & $\begin{array}{c}>90 \text { th } \\
\text { percentile } \\
(\mathrm{N}=456)\end{array}$ & $\begin{array}{c}\leq 90 \text { th } \\
\text { percentile } \\
(\mathrm{N}=4680)\end{array}$ & $\mathrm{p}$ & $\begin{array}{c}>90 \text { th } \\
\text { percentile } \\
(\mathrm{N}=468)\end{array}$ & $\begin{array}{c}\leq 90 \text { th } \\
\text { percentile } \\
(\mathrm{N}=4668)\end{array}$ & $\mathrm{p}$ \\
\hline Sleep [n $(\%)]$ & $38(9.18)$ & & & $41(8.99)$ & $382(8.16)$ & 0.54 & $51(10.90)$ & $372(7.97)$ & 0.03 \\
\hline Attention [n (\%)] & $47(11.35)$ & $461(9.76)$ & 0.30 & $53(11.62)$ & $455(9.72)$ & 0.19 & $59(12.61)$ & $449(9.62)$ & 0.04 \\
\hline
\end{tabular}

$\mathrm{N}$ - number of respondents.

${ }^{a}$ Control group. 
a)

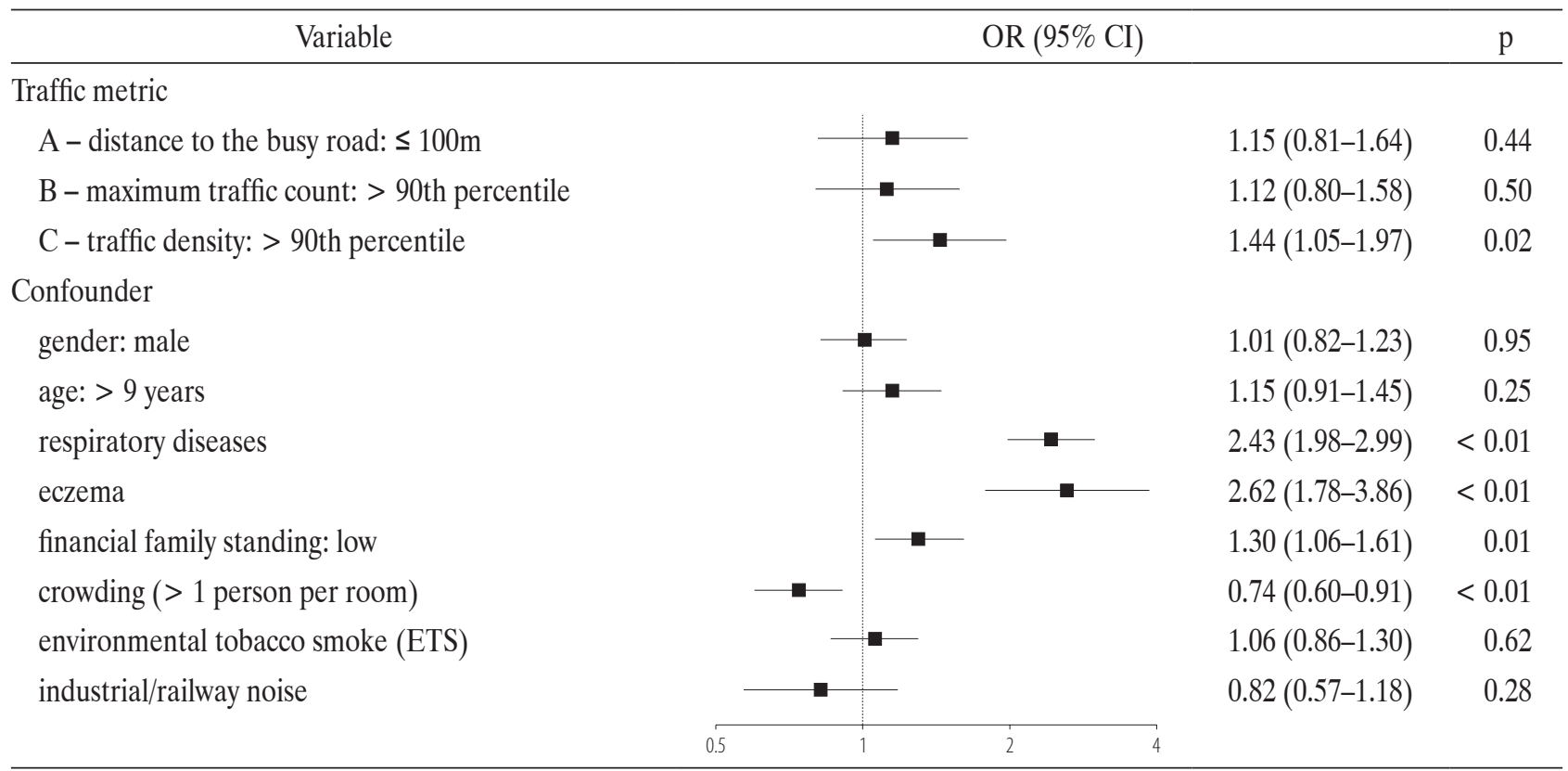

b)

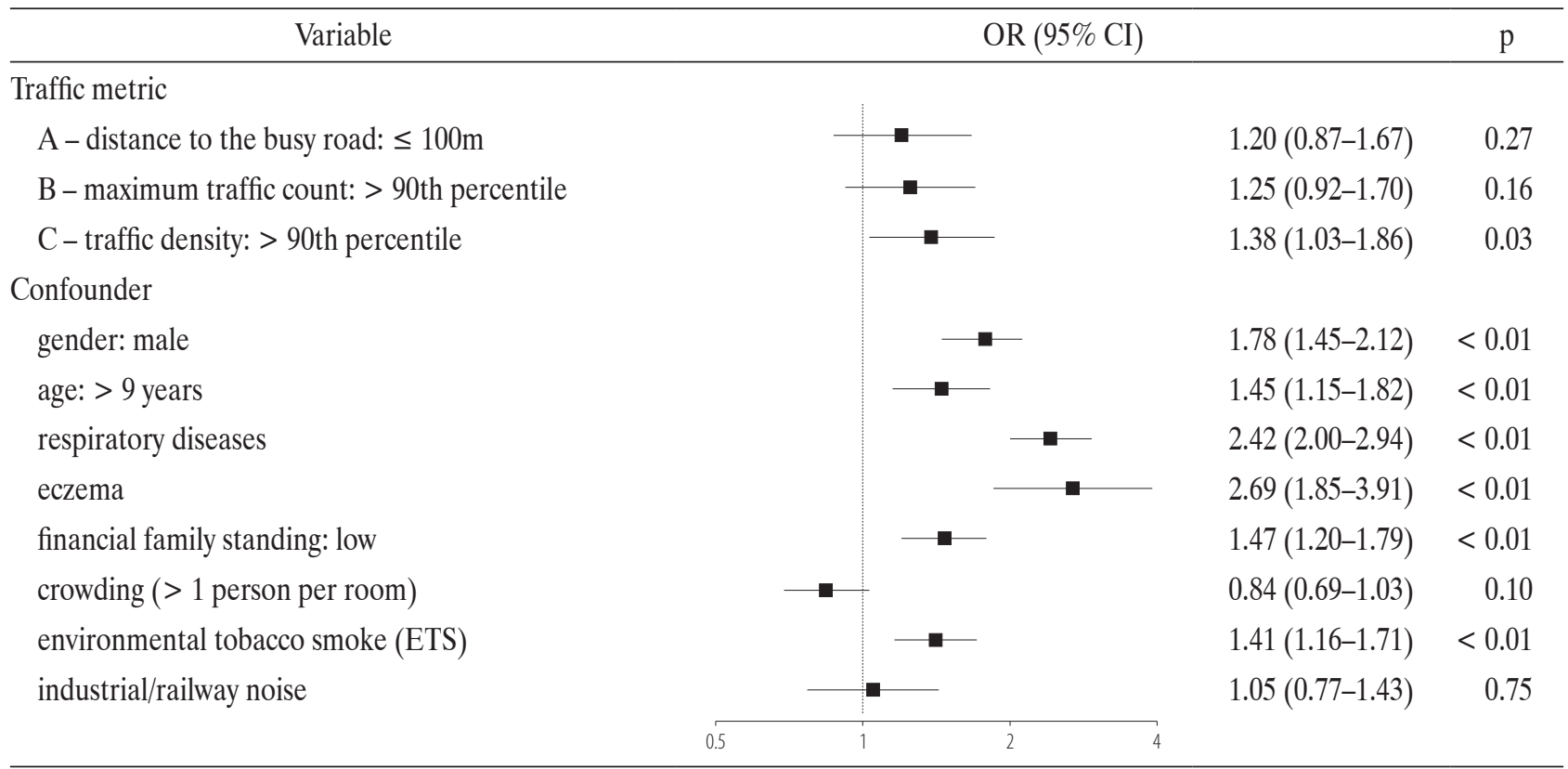

A, B, C-scenario.

Fig. 3. Final stepwise logistic regression model $(\mathrm{N}=5136)$ : adjusted for confounders association between a) traffic metrics and sleep disturbances, b) traffic metrics and attention disorders among school children living in the Upper Silesian Industrial Zone, Poland, 2003-2007 
(sleep disturbances and attention disorders, respectively) and exposure to traffic noise (distance to busy road, maximum traffic count, and traffic density) adjusted for confounders (gender, age, respiratory diseases, eczema, financial family standing, crowding, exposure to environmental tobacco smoke at home, and industrial or railway noise). The results have confirmed the statistically significant relationship between the both studied health disorders and only traffic density, which is described in the scenario C. It is worth noting that the odds of sleep disturbances and attention disorders were over 2 times greater among children with respiratory diseases or eczema. The lower family financial standing also significantly influenced the declared sleep disturbances and attention disorders. Moreover, males over 9 years old with exposure to environmental tobacco smoke (ETS) were observed to be statistically significant to have higher odds of attention disorders.

\section{DISCUSSION}

The obtained results have confirmed that higher frequency of sleep disorders among children living in the area with high traffic density is likely to be related to the traffic noise exposure. Children's health, including disorders associated with environmental noise, is an important public health issue [2]. The World Health Organization (WHO) reported that sleep disturbances and annoyance were mostly related to road traffic noise, and its estimates of the Disability-Adjusted Life Years (DALYs) for environmental noise indicate that children living in the EU countries lost 45000 years due to cognitive impairment. It is worth mentioning that the possibility of assessing the disease burden associated with this factor in the whole of the WHO European Region is limited because of the lack of exposure data in southeastern Europe (including Poland). The proper physical and mental development of children depends on living environment, and recent publications have, among others, indicated the negative impact of noise generated by traffic [29]. The necessity of reducing the exposure to excessive level of noise emitted by car traffic is also pointed out in the 6th operational objective point of the National Health Programme, which is currently being implemented in our country [30].

Such exposure may cause a number of health issues including sleep disturbances and attention disorders [8,31]. The results of our study indicate that the prevalence of sleep disturbances and attention disorders among the children at the age of 7-14 years old living in Bytom, Poland, was $8.2 \%$ and $9.9 \%$, respectively. Similar data was observed for 10-year-old children in Munich, Germany, where the frequency of sleep disorders was $12.9 \%$ and sleeping problems of studied children were associated with nocturnal noise related to traffic [19]. Our findings have confirmed that the higher frequency of sleep disorders, among children living in one of Polish cities, is likely to be related to the traffic noise exposure in the place of residence. Nevertheless, it is noteworthy how the results of our research depend on scenarios used for describing traffic. The statistically significant higher frequency of sleep disturbances and attention disorders in the exposed group was observed only for the scenario $\mathrm{C}$, which incorporated the traffic density as an index of noise exposure $(\mathrm{OR}=1.44 ; 95 \%$ CI: 1.05-1.97, and $\mathrm{OR}=1.38 ; 95 \% \mathrm{CI}: 1.03-1.86$, respectively).

The scenarios A and B were based on rather simple measures: the distance from the main road and the maximum traffic intensity near the place of residence, respectively whereas the $\mathrm{C}$ scenario incorporated overall traffic intensity and the length of road segments within defined radius $(\mathrm{r}=100 \mathrm{~m}$ ) of the place of residence. It is almost impossible to compare our results with published papers because majority of the research was either based on direct measurements of noise in the place of children's residence or utilized acoustic models for the analyzed region. Yet in general, our findings are coherent to the extent of the relation between elevated frequency of sleep disturbances or attention disorders among children and noise intensity. It 
is worth noting that at the time of collecting the data on children's health status there were no acoustic models available for the city of Bytom. Thus, we decided to use surrogates of exposure to the traffic noise, in the form of the scenarios A, B and C, described in the Material and Methods section.

The results of our study suggest that the traffic density near the place of residence (the scenario $\mathrm{C}$ ) was the best proxy of the noise exposure in the context of the frequency of sleep disturbances and attention disorders among studied children. The scenarios A and B did not confirm the relationship between traffic noise and occurrence of studied health outcomes. It is also important to admit that the use of surrogates to noise exposure (the scenarios A, B and C) allowed us to focus only on one specific source of the noise - in this case - caused by car traffic, while controlling other sources, like municipal or industrial noise.

There are also several noteworthy limitations of our research. The cross-sectional design of the study has a limited power to investigate the association between environmental exposure and the outcome. Data on children's health status was collected by means of a questionnaire and the response rate was $68.5 \%$. Moreover, due to missing data, $39 \%$ of the records were removed from the database, which could possibly introduce a bias to the presented results. To reduce another potential source of bias, children living in the centre of the city and due to a lower socio-economic status (Figure 1) were removed from the study. Another limitation of our research is the lack of data on the floor and a side of the building where the child's sleeping room was placed, moreover we were unable to control neighborhood noise. There are also some limitations of the multivariable logistic regression model [32]. The explanatory variables should be independent from one another, therefore we checked the correlation between the confounders, tolerance and VIF in our models. Moreover, large sample sizes are required in such models, with our data fulfilling this assumption $(\mathrm{N}=5136)$.
Bearing in mind all the limitations, we believe that our study has confirmed some plausible adverse health effects of traffic noise. It is worth noting that the final size of the study group $(\mathrm{N}=5136)$ complies with the criteria required for the cross-sectional study. The general public interest in the impact of living environment on the health and quality of life in our region of study [33] makes one's own observation an important voice as far as public health is concerned. Obtained results may be precious for public health experts and decisionmakers in the range of future studies and planned activities in the field of environmental health.

\section{CONCLUSIONS}

The most precise method to determine traffic noise exposure among children seems to be the traffic density within $100 \mathrm{~m}$ radius of the place of residence. Exposure to the traffic noise, in the studied population, was recognized as a significant risk factor for sleep disturbances and attention disorders among children living in the area with high traffic density.

Obtained results have confirmed that noisy exposure is an important issue of public health and calls for further studies.

\section{REFERENCES}

1. World Health Organization. Night noise guidelines for Europe [Internet]. Copenhagen: The Organization; 2009 [cited 2015 Mar 06]. Available from: http://www.euro.who.int/_ data/assets/pdf_file/0017/43316/E92845.pdf.

2. World Health Organization. Burden of disease from environmental noise. Quantification of healthy life years lost in Europe [Internet]. Copenhagen: The Organization; 2011 [cited 2015 Mar 06]. Available from: http://www.euro.who. int/_data/assets/pdf_file/0008/136466/e94888.pdf?ua = 1 .

3. Stansfeld S, Haines M, Brown B. Noise and health in the urban environment. Rev Environ Health. 2000;15(1-2):43-82, https://doi.org/10.1515/reveh.2000.15.1-2.43. 
4. European Environment Agency. Transport at a crossroads: TERM 2008: Indicators tracking transport and environment in the European Union [Internet]. Luxembourg: Office for Official Publications of the European Communities; 2009 [cited 2015 Mar 06]. Available from: http://www.eea.europa. eu/publications/transport-at-a-crossroads/download.

5. Environment Protection Authority [Internet]. Sydney South: The Authority; 2013 [cited 2015 Mar 06]. Dealing with neighbourhood noise. Preventing neighbourhood noise. Available from: http://www.epa.nsw.gov.au/noise/neighbourhoodnoise.htm.

6. Hygge S, Evans GW, Bullinger M. A prospective study of some effects of aircraft noise on cognitive performance in schoolchildren. Psychol Sci. 2002;13:469-74, https://doi. org/10.1111/1467-9280.00483.

7. Van Kempen E, van Kamp I, Lebret E, Lammers J, Emmen H, Stansfeld S. Neurobehavioral effects of transportation noise in primary schoolchildren: A cross-sectional study. Environ Health 2010;9:25-38, https://doi.org/10.1186/1476069X-9-25.

8. Stansfeld SA, Berglund B, Clark C, Lopez-Barrio I, Fischer P, Ohrström E, et al. Aircraft and road traffic noise and children's cognition and health: A cross-national study. Lancet. 2005;365(9475):1942-9, https://doi.org/10.1016/S01406736(05)66660-3.

9. Clark C, Martin R, van Kempen E, Alfred T, Head J, Davies HW. Exposure-effect relations between aircraft and road traffic noise exposure at school and reading comprehension: The RANCH project. Am J Epidemiol. 2006;163(1):27-37, https://doi.org/10.1093/aje/kwj001.

10. Papanikolaou M, Skenteris N, Piperakis SM. Effect of external classroom noise on schoolchildren's reading and mathematics performance: Correlation of noise levels and gender. Int J Adolesc Med Health. 2015;27(1):25-9, https://doi. org/10.1515/ijamh-2014-0006.

11. Pujol S, Levain JP, Houot H, Petit R, Berthillier M, Defrance J, et al. Association between ambient noise exposure and school performance of children living in an urban area: A cross-sectional population-based study. J Urban Health. 2014;91(2):256-71, https://doi.org/10.1007/s11524013-9843-6.

12. Clark C, Crombie R, Head J, van Kamp I, van Kempen E, Stansfeld SA. Does traffic-related air pollution explain associations of aircraft and road traffic noise exposure on children's health and cognition? A secondary analysis of the United Kingdom sample from the RANCH project. Am J Epidemiol. 2012;176(4):327-37, https://doi.org/10.1093/aje/ kws012.

13. Regecová V, Kellerová E. Effects of urban noise pollution on blood pressure and heart rate in preschool children. J Hypertens. 1995;13(4):405-12, https://doi.org/10.1097/00004872-19 9504000-00005.

14. Belojevic G, Jakovljevic B, Stojanov V, Paunovic K, Ilic J. Urban road-traffic noise and blood pressure and heart rate in preschool children. Environ Int. 2008;34(2):226-31, https://doi.org/10.1016/j.envint.2007.08.003.

15. Babisch W, Neuhauser H, Thamm M, Seiwert M. Blood pressure of 8-14 year old children in relation to traffic noise at home - Results of the German Environmental Survey for Children (GerES IV). Sci Total Environ. 2009;407(22): 5839-43, https://doi.org/10.1016/j.scitotenv.2009.08.016.

16. Kelishadi R, Poursafa P, Keramatian K. Overweight, air and noise pollution: Universal risk factors for pediatric pre-hypertension. J Res Med Sci. 2011;16(9):1234-50.

17. Liu C, Fuertes E, Tiesler CM, Birk M, Babisch W, Bauer CP, et al. The associations between traffic-related air pollution and noise with blood pressure in children: Results from the GINIplus and LISAplus studies. Int J Hyg Environ Health. 2014;217(4-5):499-505, https://doi.org/10.1016/j.ij heh.2013.09.008.

18. European Environment Agency. Are we moving in the right direction? Indicators on transport and environmental integration in the EU. TERM 2000 [Internet]. Copenhagen: The Agency; 2000. p. 32-4 [cited 2015 Mar 06]. Available from: http://www.eea.europa.eu/publications/ENVISSUENo12/ at_download/file. 
19. Tiesler CM, Birk M, Thiering E, Kohlböck G, Koletzko S, Bauer CP, et al. Exposure to road traffic noise and children's behavioural problems and sleep disturbance: Results from the GINIplus and LISAplus studies. Environ Res. 2013;123:1-8, https://doi.org/10.1016/j.envres.2013.01.009.

20. Haines MM, Stansfeld SA, Brentnall S, Head J, Berry B, Jiggins M, et al. The West London Schools Study: The effects of chronic aircraft noise exposure on child health. Psychol Med. 2001;31(8):1385-96, https://doi.org/10.1017/ S003329170100469X.

21. Ising H, Ising M. Chronic cortisol increases in the first half of the night caused by road traffic noise. Noise Health. 2002;4(16):13-21.

22. Paunovic K, Belojevic G, Jakovljevic B. Blood pressure of urban school children in relation to road-traffic noise, traffic density and presence of public transport. Noise Health. 2013;15(65):253-60, https://doi.org/10.4103/14631741.113521.

23. Lee EY, Jerrett M, Ross Z, Coogan PF, Seto EY. Assessment of traffic-related noise in three cities in the United States. Environ Res. 2014;132:182-9, https://doi.org/10.1016/j.envres.2014.03.005.

24. Opoczyński K. [General traffic measure]. Warszawa: General Directorate for National Roads and Highways; 2006. Polish.

25. Skrzypek M, Zejda JE, Kowalska M, Czech EM. Effect of residential proximity to traffic on respiratory disorders in school children in upper Silesian Industrial Zone, Poland. Int J Occup Med Environ Health. 2013;26(1):83-91, https:// doi.org/10.2478/s13382-013-0078-2.

26. Méline J, Van Hulst A, Thomas F, Karusisi N, Chaix B. Transportation noise and annoyance related to road traffic in the
French RECORD study. Int J Health Geogr. 2013;12:44-57, https://doi.org/10.1186/1476-072X-12-44.

27. Mickey RM, Greenland S. The impact of confounder selection criteria on effect estimation. Am J Epidemiol. 1989;129(1):125-37, https://doi.org/10.1093/oxfordjournals. aje.a115101.

28. Bursac Z, Gauss CH, Williams DK, Hosmer DW. Purposeful selection of variables in logistic regression. Source Code Biol Med. 2008;3:17-25, https://doi.org/10.1186/1751-0473-3-17.

29. Seidman MD, Standring RT. Noise and quality of life. Int J Environ Res Public Health. 2010;7(10):3730-8, https://doi. org/10.3390/ijerph7103730.

30. Ministry of Health. National Health Programme for the years 2007-2015. Annex to the Resolution of the Council of Ministers No. 90/2007 of 15 May 2007 [Internet]. Warszawa: The Ministry; 2007 [cited 2015 Mar 06]. Available from: http://www.mz.gov.pl/_data/assets/pdf_file/0003/ 15843/1943_001pop.pdf.

31. Halonen JI, Vahtera J, Stansfeld S, Yli-Tuomi T, Salo P, Pentti J, et al. Associations between nighttime traffic noise and sleep: The Finnish Public Sector Study. Environ Health Perspect. 2012;120(10):1391-6, https://doi.org/10.1289/ehp. 1205026.

32. Bewick V, Cheek L, Ball J. Statistics review 14: Logistic regression. Crit Care. 2005;9(1):112-8, https://doi.org/10.1186/ cc3045.

33. Kowalska M, Danso F, Humeniuk M, Kułak E, Arasiewicz H. Determinants of environmental domain of quality of life in economically active population living in Silesian Agglomeration, Poland. Int J Occup Med Environ Health. 2013;26(1):132-43, https://doi.org/10.2478/s13382-013-0081-7.

This work is available in Open Access model and licensed under a Creative Commons Attribution-NonCommercial 3.0 Poland License - http://creativecommons.org/ licenses/by-nc/3.0/pl/deed.en. 